\title{
Factorial Invariance of Self-efficacy in Physical Health Care Scale for Men and Women University Students
}

\author{
Judith M. Rodriguez-Villalobos, Dr. \\ Luis H. Blanco Vega, Md. \\ Martin A. Gonzalez, M.A. \\ Yunuen Rangel Ledezma, M.P. \\ Faculty of Physical Culture Sciences, \\ Autonomous University of Chihuahua, México
}

doi: 10.19044/esj.2016.v12n1p514 URL:http://dx.doi.org/10.19044/esj.2016.v12n1p514

\begin{abstract}
The present study analyses the psychometric properties of the Selfefficacy in Physical Health Care Scale. The overall sample consisted of 2006 subjects: 902 women and 1104 men, with a mean age of 18.53 years (SD= $1.52)$ and 18.84 years $(S D=1.55)$ respectively. The Factorial Psychometric analysis showed that a three-factorial structure (nutrition, physical health and hydration) was viable and adequate for both populations (men and woman) according to the established psychometric requirements when the informers are the students themselves. The results showed that factor structure, factor loadings and intercepts of the instrument could be considered invariant across groups; however, there are differences between groups in favor of men for the means of the nutrition and physical health factors.
\end{abstract}

Keywords: Self-efficacy, factor structure, measurement invariance, multisample confirmatory factor analysis

\section{Introduction:}

Self-efficacy refers to the belief that one can achieve the desired results and is a central construct in Bandura's social cognitive theory (Bandura, 1986, 2012). According to the theory, self- efficacy of an individual is a fundamental factor in the interaction between the environment and the behavior of the individual (Bandura, 2012). Self-efficacy can be specific or general. The specific self-efficacy describes the beliefs of an individual on which he can achieve good results in a defined area of his life, for example their academic performance. While the general self-efficacy is 
in a sense overall the individual's competence in handling a variety of life challenges. Both types of self-efficacy are relatively stable and can be characterized as traits (Yeo \& Neal, 2006).

According to the formulations of Bandura (Bandura, 1977, 1986, 1992) when a person attempts the possibility to perform a healthy behavior or change a bad habit there are three elements that explain the resulting decision: a) the belief that a determined situation is harmful, b) the belief that a behavior change can reduce the supposed threat c) the belief that it is competent enough to adopt a good conduct or to stop practicing one that would be harmful. It is this last aspect that suggests the concept of selfefficacy expectations: beliefs about the ability to exercise control over their own behavior and the environment in which it takes place.

From the Social Learning Theory Bandura is then assumed that selfefficacy expectations are an important predictor of the intentions and actions of individuals facing various situations (Schwarzer, 1992). Because a high level of perceived self-efficacy has been shown as a protective element which increases the motivation (Bandura, Barbaranelli, Caprara, \& Pastorelli, 1996), reduce emotional disturbances (Villamarín, 1990a), at the same time improves healthy behaviors and physical care (Villamarín, 1990b). In fact, compared to how difficult it can be to encourage the adoption of behaviors that promote health or stop harmful behavior against it, self-efficacy has been consistently shown to be a major factor (Bandura, 1997).

Therefore, perceived self-efficacy plays a key role in human functioning since, affects behavior not only directly, but also for its impact on other key determinants such as goals and aspirations, outcome expectations, affective tendencies and perception of the impediments and opportunities that arise in the social environment (Bandura, 1992, 1997; Sansinenea et al., 2008).

This instrumental study (Montero \& León, 2005) aims to provide empirical support for the factorial division of Self-Efficacy in Physical Health Care Scale in Mexican university students; which it is justified by the importance of checking the factorial structure and the psychometric equivalence of the instrument in different groups; since in the context of intergroup comparison, it is essential to consider the need to carry out the adaptation of an instrument of psychological measure fulfilling all the criteria of equivalence, but above all consider whether the same factor structure is applicable to different groups of individuals (Abalo, Lévy, Rial, \& Varela, 2006; Arbuckle, 2012).

This paper aims, on the one hand, to investigate whether the psychometric results proposed by (Ornelas, Blanco, Rodríguez, \& Flores, 2011) for the Self-Efficacy in the Physical Health Care Scale are replicate 
and, secondly, expand them. To do this, first it will be checked the degree of congruence of the factorial structure of the scale obtained in this study and the one reported by (Ornelas et al., 2011). Secondly, the factorial invariance between the samples of the present study is calculated.

\section{Method:}

\section{Participants}

The sample of 2006 participants, 902 (45\%) woman and 1104 (55\%) men, was obtained by a convenience sample, trying to cover the representation of the different degrees offered at the Autonomous University of Chihuahua. Women ages was ranging between 17 and 25 years, with a mean of 18.53 and a standard deviation of 1.52 years; and men ages was ranging between 17 and 25 years, with a mean of 18.84 and standard deviation of 1.55 years.

\section{Instrument}

Self-Efficacy in the Physical Health Care Scale designed by (Ornelas et al., 2011) is a Likert questionnaire assisted by computer of 6 items related to behaviors of health care; where the respondent answers on a scale of $0-10$, how often currently, ideally if he strives to change, would make or manifest an action (Figure 1).

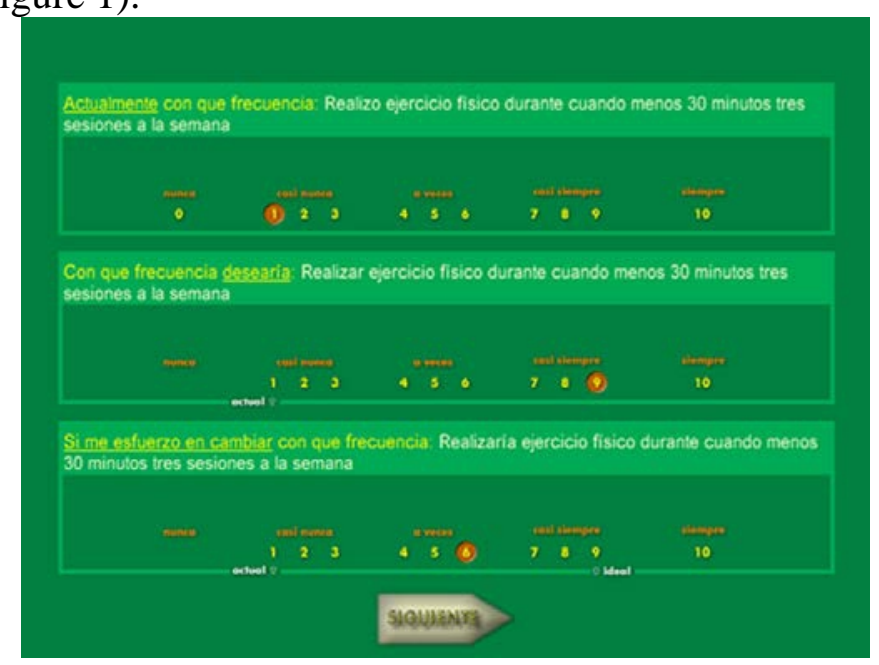

Figure 1. Example Response for each item of the questionnaire.

Although each individual responded to the 6 items of the instrument in three different scenarios: scenario perceived ability, scenario of interest in being capable and scenario of being able to change ad; in the psychometric analysis only the answers to the first stage were used 


\section{Procedure}

Students of the degrees offered at the Autonomous University of Chihuahua were invited to participate; those who agreed to participate signed a consent letter. Then, the instrument explained above was applied through a computerized application using the instrument administrator module of scales editor, version 2.0 (Blanco et al., 2013) in a session of about 25 minutes in the computer labs correspondent to each participating academic unit.

At the beginning of each session students were given a brief introduction on the importance of the study and how to access the instrument; instructions of how to answer were on the first computer screens, before the first instrument item.

At the end of the session students were thanked for their contribution to the study.

Once the instrument was applied, data was collected by the results generator module of scales editor, version 2.0 (Blanco et al., 2013).

\section{Data Analysis}

The psychometrical analysis was applied in two stages: 1) Factorial Confirmatory Analysis and 2) Invariance Factorial Analysis; so that it could obtain evidence that presents the best properties for the scores confirmation of self-efficacy in physical health care on men and women university students.

To conduct the confirmatory factorial analysis for each sample, AMOS 21 software was used (Arbuckle, 2012), variances in terms of error were specified as free parameters, in every latent variable (factor) a structural coefficient was set associated to one, so that scale was equal to the superficial variables (items). The estimated method used was the maximum credibility; following the recommendation of (Thompson, 2004), so when the confirmatory factorial analysis is used, it is necessary to verify not only the adjustment of the theoretical model but it is recommended to compare the fit indices of some alternative models to select the best.

To evaluate the adjustment model, statistical chi-squared, the Goodness-of-fit index (GFI) adjustment, and the root mean square error of approximation (RMSEA) were used as absolute adjustment measures. Adjusted goodness of fit index (AGFI) the Tucker-Lewis Index (TLI), the comparative fit index (CFI) as measures of increasing adjustment. Parsimony normed fit index (PNFI), the Parsimony Good-ness-of-fit index (PGFI), the chi-squared fit index divided by degrees of freedom (CMIN/GL) and the Akaike Information Criterion (AIC) as adjusting measures of Parsimony (Gelabert et al., 2011). 
Finally, an analysis of the factorial invariance of the models of measurement obtained was made, following the recommendations of (Abalo et al., 2006), and was calculated the reliability of each of the dimensions through Cronbach's alpha and Omega coefficient (Revelle \& Zinbarg, 2009).

\section{Results}

\section{Confirmatory Factorial Analysis}

According to the results obtained in Table1 in the Confirmatory Factorial Analysis of 6 items grouped in three factors in the sample of women is optimal (GFI .990 y RMSEA .064) and according to the incremental adjustment measures and Parsimony meaningfully superior to the in-dependent model and very similar to the saturated model.

Furthermore, confirmatory factor analysis on the sample of men (Table 1) shows again the measuring model of two factors is optimal (GFI .996 y RMSEA .032) and according to the incremental adjustment measures and Parsimony meaningfully superior to the independent model and very similar to the saturated model.

According to the results of Table 2, in both samples, most of the items properly saturate in their dimension (factor) provided. It was observed moderate intercorrelations among the factors, demonstrating adequate discriminant validity.

Invariance of the factorial structure among men and women university students

The fit indices obtained (table 3) allows to accept the equivalence of the base measuring model among the two samples. Although the value of chi-squared exceeds the demanded one to accept the invariance hypothesis, the rest of the indices contradict this conclusion (GFI .993; CFI .989; RMSEA .035; AIC 101.250) this allows us to accept the base model of invariance (model without restrictions).

Adding the base model restrictions on factorial charges, metric invariance is characterized. Values obtained from table 3 permit to accept this invariance level. The Goodness of fit index (GFI $=.993)$ and root mean square error of approximation (RMSEA $=.031$ ) continue offering convergent information in this direction. Besides Akaike information criterion (AIC= 518.842) and Bentler comparative fit index (CFI = .989) do not suffer big variations toward the previous model. Using the criteria for the evaluation of the nested models proposed by Cheung and Rensvold (2002) who suggest that if the calculation of the difference of the CFI of both nested models diminish in .01 or less, the restricted model is taken for granted therefore the compliance of the factorial invariance. The difference of the CFIs obtained 
allows to accept the metrical invariance model. We can conclude up to this point that factorial charges are equivalent in the two samples.

Having demonstrated the metric invariance between samples, we evaluate the equivalence between intercepts (strong factorial invariance). The Indices (Table 3) show a good adjustment of this model, evaluated independent as well as analyzed toward nesting with the metric invariance model. The difference between the two comparative indices of Bentler is .002; and the general adjustment index is .991 and the root mean square error of approximation is .029. Accepted then the strong invariance, the two evaluated models are equivalent toward the factorial coefficients and the intercepts.

Table 1. Absolute, incremental and Parsimony fit indices for the generated models. Confirmatory factor analysis for women and men.

\begin{tabular}{|c|c|c|c|c|c|c|c|c|}
\hline \multirow[b]{2}{*}{ Model } & \multicolumn{3}{|c|}{ Absolute indices } & \multicolumn{3}{|c|}{ Incremental indices } & \multicolumn{2}{|c|}{ Parsimony indices } \\
\hline & $\chi^{2}$ & GFI & RMSEA & AGFI & TLI & CFI & CMIN/DF & AIC \\
\hline \multicolumn{9}{|c|}{ Factor solution for women } \\
\hline Independent & $1259.035^{*}$ & .441 & .303 & .465 & .000 & .000 & 83.936 & 1271.035 \\
\hline Saturated & 0.000 & 1.000 & & & 1.000 & 1.000 & & 42.000 \\
\hline 3 factors & $28.292 *$ & .990 & .064 & .963 & .955 & .982 & 4.715 & 58.292 \\
\hline \multicolumn{9}{|c|}{ Factor solution for men } \\
\hline Independent & $1426.694^{*}$ & .629 & .292 & .480 & .000 & .000 & 95.113 & 1438.694 \\
\hline Saturated & 0.000 & 1.000 & & & 1.000 & 1.000 & & 42.000 \\
\hline 3 factors & $12.959 *$ & .996 & .032 & .986 & .988 & .995 & 2.160 & 42.959 \\
\hline
\end{tabular}

Note: ${ }^{*} \mathrm{p}<.05$; GFI = goodness of fit index; RMSEA = root mean square error of approximation; AGFI = adjusted goodness of fit index; TLI = Tucker-Lewis index; CFI = comparative fit index; CMIN/DF = chi-squared fit index divided by degrees of freedom; AIC = Akaike information criterion

The factors obtained in the confirmatory factor analysis reached internal consistency values equal or greater than .60 in both samples (male and female); demonstrating adequate internal consistency for these subscales, particularly when it is considered the small number of items (Table 4).

Contrasts of the means of the factors among women and men

Once proved the factorial invariance, the differences among the means of the factors from the two groups were estimated taking as a reference the men's sample, establishing 0 as the value of the means for this sample, considering freely the value of the means for the sample of women. Restrictions about regression coefficients and intercepts required for the contrast among the means made automatically through the software AMOS 21 (Arbuckle, 2012). The results of the comparisons between means indicated that the mean of the Nutrition and Physical Health factors were significantly lower (-0631, $\mathrm{p}<0.001$ and $1146, \mathrm{p}<0.001$ respectively) in women; with no difference in the Hydration factor. 
Table 2 Standardized solutions for the confirmatory factor analysis in both samples.

\begin{tabular}{|c|c|c|c|c|c|c|}
\hline \multirow[b]{3}{*}{ Item } & \multicolumn{4}{|c|}{ Factor weights } & & \\
\hline & \multicolumn{2}{|c|}{ Nutrition } & \multicolumn{2}{|c|}{ Physical health } & \multicolumn{2}{|c|}{ Hydration } \\
\hline & women & men & women & men & women & men \\
\hline 2 I make three meals a day & .74 & .77 & & & & \\
\hline 4 I have set hours for my meals & .81 & .70 & & & & \\
\hline $\begin{array}{l}1 \text { I take good care of myself } \\
\text { physically }\end{array}$ & & & .75 & .72 & & \\
\hline $\begin{array}{l}3 \text { I make physical exercise for } \\
\text { at least } 30 \text { minutes three } \\
\text { sessions a week }\end{array}$ & & & .63 & .70 & & \\
\hline $\begin{array}{l}5 \text { I drink more than } 6 \text { glasses of } \\
\text { water a day }\end{array}$ & & & & & .55 & .52 \\
\hline $\begin{array}{l}6 \text { I consume } 2 \text { or more pieces of } \\
\text { fruit a day }\end{array}$ & & & & & .81 & .79 \\
\hline \multicolumn{7}{|c|}{ Correlations between factors } \\
\hline Nutrition & - & - & & & & \\
\hline Physical health & .57 & .54 & - & - & & \\
\hline Hydration & .57 & .59 & .57 & .66 & - & - \\
\hline
\end{tabular}

Table 3 Goodness of fit indices of each of the models tested in the factorial invariance.

\begin{tabular}{|c|c|c|c|c|c|c|c|}
\hline \multirow[t]{2}{*}{ Model } & \multicolumn{7}{|c|}{ Fit Indices } \\
\hline & $\chi^{2}$ & gl & GFI & NFI & CFI & RMSEA & AIC \\
\hline $\begin{array}{l}\text { Model without } \\
\text { restrictions }\end{array}$ & $41.250 *$ & 12 & .993 & .985 & .989 & .035 & 101.250 \\
\hline Metric Invariance & $43.202 *$ & 15 & .993 & .984 & .989 & .031 & 97.202 \\
\hline Strong factor invariance & $55.602 *$ & 21 & .991 & .979 & .987 & .029 & 97.602 \\
\hline
\end{tabular}

Note: ${ }^{*} \mathrm{p}<.05$; GFI = goodness of fit index; NFI = normed fit index; CFI = comparative fit index; RMSEA = root mean square error of approximation; AIC = Akaike information criterion

Table 4 Coefficient omega and alpha for the factors obtained.

\begin{tabular}{lcccc}
\hline \multirow{1}{*}{ Factor } & \multicolumn{2}{c}{ Women } & \multicolumn{3}{c}{ Men } \\
\cline { 2 - 5 } & $\boldsymbol{\Omega}$ & $\mathrm{a}$ & .70 & $\mathrm{a}$ \\
\hline 1. Nutrition & .75 & .75 & .70 \\
2 Physical health & .65 & .60 & .67 & .62 \\
3. Hydration & .64 & .61 & .61 & .60 \\
\hline
\end{tabular}

\section{Discussion:}

From the results, analysis and discussion shown, and taking in consideration the main objective of this study which was to examine the factorial structure and the measure of the invariance of this structure in university students, we can conclude the following:

1) The Confirmatory Factorial Analysis, in both samples, indicated that the adjustment of the data to the theoretical model of 6 grouped items in 
three factors is optimal. At the same time that the three factors obtained present in general adequate standardized factorial saturations. Meanwhile the factors correlate among themselves in a positive way and statistically significant, which shows that, as Self-Efficacy perceived increases in some of the factors, the other factor increases as well. Results corresponding to those obtained by (Ornelas et al., 2011).

2) The factors in both samples showed adequate internal consistency, particularly when considering the small number of items in each.

3) Along with all the above, the results of the analysis of the factorial invariance between samples; indicate a high congruence between pairs of factors. Suggesting the existence of strong evidence of cross-validation of the measure and therefore the stability of the structure, until is proved the contrary.

4) The comparisons between the groups reflect significant differences in favor to men, in the mean of two of the factors. Suggesting that men perceive a little more self-efficient than women in Nutrition and Physical health factors.

\section{Conclusion:}

The analysis of the psychometric properties has shown that a three-factor structure is viable and appropriate in accordance with established psychometric requirements when informants are the students themselves. The structure of three factors, based on statistical and substantive criteria, has shown adequate indicators of adjustment, reliability and validity. However, we believe that further studies are necessary in order to corroborate or refute the data obtained in this investigation.

\section{References:}

Abalo, J., Lévy, J., Rial, A., \& Varela, J. (2006). Invarianza factorial con muestras múltiples. In J. Lévy (Ed.), Modelización con Estructuras de Covarianzas en Ciencias Sociales (pp. 259-278). Madrid: Netbiblo.

Arbuckle, J. R. (2012). AMOS users guide version 21.0. Chicago, IL: Marketing Department, SPSS Incorporated.

Bandura, A. (1977). Social Learning Theory. New York: General Learning Press.

Bandura, A. (1986). Social foundations of thought and action: A social cognitive theory. Englewood Cliffs, NJ: Prentice Hall.

Bandura, A. (1992). Exercise of personal agency throught the self-efficacy mechanism. In R. Schwarzer (Ed.), Self-efficacy: thought control of action (pp. 3-38). Washington D C: Hemisphere.

Bandura, A. (1997). Self-efficacy: The exercise of Control. New York: Freeman. 
Bandura, A. (2012). On the Functional Properties of Perceived Self-Efficacy Revisited. Journal of Management, 38(1), 9-44. doi: 10.1177/0149206311410606

Bandura, A., Barbaranelli, C., Caprara, G. V., \& Pastorelli, C. (1996). Multifaceted impact of self-efficacy beliefs on academic functioning. Child Development, 67(3), 1206-1222.

Blanco, H., Ornelas, M., Tristán, J. L., Cocca, A., Mayorga-Vega, D., LópezWalle, J., \& Viciana, J. (2013). Editor for creating and applying computerise surveys. Procedia Social and Behavioral Sciences, 106, 935-940. doi: http://dx.doi.org/10.1016/j.sbspro.2013.12.105

Gelabert, E., García-Esteve, L., Martín-Santos, R., Gutiérrez, F., Torres, A., \& Subirà, S. (2011). Psychometric properties of the Spanish version of the Frost Multidimensional Perfectionism Scale in women. Psicothema, 23(1), 133-139.

Montero, I., \& León, O. (2005). Sistema de clasificación del método en los informes de investigación en Psicología. International Journal of Clinical and Health Psychology, 5, 115-127.

Ornelas, M., Blanco, H., Rodríguez, J. M., \& Flores, F. J. (2011). Análisis psicométrico de la escala autoeficacia en conductas de cuidado de la salud física en universitarios de primer ingreso. Formación Universitaria, 4(6), 2134. doi: $10.4067 / S 0718-50062011000600004$

Revelle, W., \& Zinbarg, R. E. (2009). Coefficients alpha, beta, omega and the glb: comments on Sijtsma. Psychometrika, 74(1), 145-154. doi: 10.1007/s11336-008-9102-z

Sansinenea, E., Gil, L., Agirrezabal, A., Larrañaga, M., Ortiz, G., Valencia, J. F., \& Fuster, M. J. (2008). Autoconcordancia y autoeficacia en los objetivos personales: ¿Cuál es su aportación al bienestar? Anales de Psicología, 24(1), 121-128.

Schwarzer, R. (1992). Self-efficacy in the adoption and maintenance of health behaviors: Theoretical approaches and a new model. In R. Schwarzer (Ed.), Thought Control of Action (pp. 217-243). Washington: Hemisphere Publishing Corporation.

Thompson, B. (2004). Exploratory and Confirmatory Factor Analysis. Understanding concepts and applications. . Washington, D C: American Psychological Association.

Villamarín, F. (1990a). Autoeficacia y conductas relacionadas con la salud. Revista de Psicología de la Salud, 2(1), 45-64.

Villamarín, F. (1990b). Papel de la autoeficacia en los trastornos de ansiedad y depresión. Análisis y Modificación de Conducta, 16(47), 55-79.

Yeo, G. B., \& Neal, A. (2006). An examination of dynamic relationship between self-efficacy and performance across levels of analysis and levels of specificity. Journal of Applied Psychology, 91(5), 1088-1101. 